\title{
Investigating the Impacts of Brand Social Media Posts' Linguistic Styles on Consumer Engagement
}

\author{
Qi Deng \\ Dalhousie University \\ Qi.Deng@dal.ca
}

\author{
Michael Hine \\ Carleton University \\ mike.hine@carleton.ca
}

\author{
Shaobo Ji \\ Carleton University \\ shaobo.ji@carleton.ca
}

\author{
Yun Wang \\ Carleton University \\ yun.wang3@carleton.ca
}

\begin{abstract}
Enhancing consumer engagement with brand posts on social media is challenging to digital marketers. However, it is unclear what contents work better for which brand and in what way. This paper investigates the impacts of three brand post linguistic styles (i.e., emotionality, complexity, and informality) and finds that brand posts' linguistic styles can impact consumer engagement. The findings improve our understanding of the role that language plays in brand communications on social media.
\end{abstract}

\section{Introduction}

Social media has become an integral part of the marketing communication mix and changed the way that brands and consumers interact with each other [1]. Currently, it is common that brands create social media accounts (e.g., Facebook brand pages, Twitter, and Instagram) and interact with consumers through regularly creating interesting posts. Consumers can follow brands and actively interact with them through engaging with (i.e., liking, sharing, or commenting on) these posts. To digital marketers, enhancing consumer engagement with brand posts on social media is both vital and challenging [2-4]. Consumer engagement with brand posts is positively related with: brand awareness, preference, and consideration [5-8]; brand equity [5, 9]; and brand performance (e.g., sales, new customer acquisition, brand value, etc.) $[2,7,10]$. Alternatively, social media marketers are struggling with designing creative brand posts that maximizes consumer engagement [11]. It has been reported that only about $1 \%$ of brands' followers on Facebook engage with brand posts [12]. Even within the most popular Facebook brand pages, the fan engagement rate is only $4.3 \%$ [13]. Therefore, in current social media marketing practices, understanding how to design brand posts that facilitate consumer engagement is an important priority [14].

Although academic research suggests that marketers can strategically design brand posts that improve consumer engagement, it is not clear what contents work better for which brand and in what way [12]. While previous research in this area has mainly focused on specific brand post characteristics, such as content type, media type, and post timing, few of them has examined the language used by brand $[6,12,15]$. Arguably, as a critical medium that communicates brand meanings, language plays a significant role in the underlying processes of consumers identifying, experiencing, integrating, signifying, and connecting with brands and affects consumers' responses to brands in terms of perception, memory, attitude, as well as behavior [16]. Branding relies heavily on language, and this is notably more evident in the social media context as brandconsumer communications on social media mostly happen through verbal cues [15-16]. Therefore, the language style of a brand may affect consumers' perception, which further influences consumers' engagement behavior [6].

In this paper, we investigate how linguistic styles of brand posts on social media influence consumer engagement. Drawing on the communication accommodation theory (CAT) and literature on computer-mediated communication (CMC), we examine the impacts of three brand post linguistic styles (i.e., emotionality, complexity, and informality) on consumer engagement. Based on the analysis of 5,997 Facebook posts collected from 42 brands, we found that brand posts' linguistic styles significantly impact consumer engagement, but the effects vary regarding the three types of consumer engagement (i.e., like, share, comment).

The findings of this paper improve our understanding of the role that brand language plays in brand communications on social media by demonstrating that consumer engagement could be enhanced through employing proper linguistic style in brand posts.

\section{Theoretical foundation and research hypotheses}




\subsection{Communication accommodation theory}

Communication accommodation theory explains how people adjust their behaviors during communications, why they do so, and the effects arising from doing so [17-18]. According to CAT, the two general communication strategies are accommodation (or convergence) and nonaccommodation (or divergence) [17]. Accommodation is a strategy whereby people adjust their communication behaviors to appear more similar to their interlocutors. Conversely, nonaccommodation is a strategy in which people accentuate differences between themselves and their interlocutors in communication behaviors [17]. According to CAT, accommodation in language leads to positive evaluations of the communication (e.g., message agreement, persuasiveness, and communication satisfaction), the interlocutor (e.g., credibility, trust, sociability, and attractiveness), and the relationship (e.g., relational satisfaction, closeness, common identity, and intimacy) [17]. For example, research has shown that language accommodation in computer-mediated communications can enhance the rapport [18] and trust [19] between communicators. Recent research has shown that language accommodation also positively impacts communicators' involvement and behavior [20]. For example, Ludwig et al. [21] found that linguistic style matching between an online product review and the interest group is positively related to conversion rates. Steinmann, Mau, \& Schramm-Klein [22] found that personalized communication style used by brands in interacting with online consumption community members can enhance members' evaluation of the community as well as increase their purchase intention.

Brand posting is a form of brand-to-consumer communication that occurs in a CMC context, i.e., social media; thus, it is reasonable to assume that language accommodation in brand posting could positively impact consumers' evaluation and behavior as well. Previous research on brand anthropomorphism has shown that consumers tend to communicate with brands in the similar way as with their interpersonal relationships and use norms of social relationships to guide their communications with brands [23]. On social media, due to the naturally interactive environment where brand-consumer interaction largely resembles interpersonal interactions, brand anthropomorphism is even more likely to occur and brand communications are more likely to be treated as interpersonal communications [24]. Consequently, in brandconsumer communications on social media, consumers will expect brands to respect the social norms and 'talk' as their other interpersonal relationships do [25]. Therefore, adopting a casual communication style in brand posts could obey consumers' perception of social media norms, fulfill the consumers' expectation, and thus enhance consumer engagement. Drawing on CAT and discussions above, we propose that accommodating to a casual linguistic style could enhance consumer engagement with the brand posts on social media. In the following sections, we will develop hypotheses regarding the linguistic features of emotionality, complexity, and informality.

\subsection{Emotionality and consumer engagement}

Emotionality refers to the emotion expressed by brand posts. As an internal state, emotion can be contagious. Dependent on the concept of emotional contagion, marketing researchers found that emotion expressed in a brand communication (e.g., advertising, service encounter) can affect how the communication is processed and influence the effects of the communication [26]. While emotional contagion effect has been mainly studied in a face-to-face context, it can happen via verbal communication solely and in CMC as well [27-28]. For example, in social media contexts, when consumers are exposed to positive messages, emotional contagion can take place and lead them to experience the same positive emotions [29]. Previous research has shown that, in CMC, emotionally-charged messages (e.g., using emotional words) can trigger more cognitive involvement (e.g., attention) [30] and higher psychological arousal [31], which, in turn, can impact the message receivers' feedback and reciprocity [32], participation [33], and social sharing behavior [34]. For example, Stieglitz \& Dang-Xuan [32] found that tweets with emotion are likely to be shared more often and more quickly than neutral ones. Kim \& Johnson [34] found that emotion in brand-related user-generated content on Facebook has an impact on consumers' emotional response, which, in turn, influences consumers' willingness to pass along the information and brand engagement. Furthermore, research on consumer engagement with brand posts has suggested that using emotional appeals in brand posts can enhance consumer engagement (e.g., number of likes, shares, and comments) [12, 35]. Therefore, we derive the following hypotheses:

H1a: Positive emotionality of brand posts is positively related to consumer engagement.

H1b: Negative emotionality of brand posts is negatively related to consumer engagement.

\subsection{Complexity and consumer engagement}

Similar to the concept of readability, message complexity decides the effort required by message receivers to read and understand the message [36]. 
Specifically, the more difficult a message is to be processed cognitively, the higher the message complexity. Previous research has shown that complexity can impact consumers' perception and the persuasiveness of the advertising [37-38]. Furthermore, research on eWOM has found that complexity is negatively related to perceived helpfulness and thus can decrease the persuasiveness of online reviews [39-40]. According to resource matching theory [41], persuasion can be maximized when the cognitive resource needed to process a message matches with the resource that is available to the message recipient so that the recipient can process the message with relative ease and pleasure [37]. In the context of social media, where information overload is ubiquitous, consumers are more likely to process social media content under low involvement/attention conditions without spending too many cognitive resources $[11,42]$. This is even more true when consumers process brand posts on social media. The recent finding that shorter Facebook posts can receive more engagement also suggests that the complexity might decrease consumer engagement [12]. Besides, research has shown that users are more likely to respond to simpler messages in overload mass interaction $[36,43]$. Therefore, we derive the following hypothesis:

H2: Complexity of brand posts is negatively related to consumer engagement.

\subsection{Informality and consumer engagement}

An informal communication style is "common, nonofficial, familiar, casual, and often colloquial, and contrasts in these senses with formal" [44]. The difference between informality and formality is often defined in accord to the difference between spoken and written languages [45]. In the social media context, informality is related to the use of some linguistic features, such as abbreviations (e.g., LOL for 'laughing out loud', OMW for 'on my way'), emojis (e.g., $\hat{\vartheta}, \hat{\theta}$, ), or non-standard spellings (e.g., hv for 'have', msg for 'message'), contractions (e.g., don't, can't, and it's), and personal pronouns (e.g., we, you, and $u s$ ) [24, 46]. Sociolinguistics research has suggested that the communication style (formal vs. informal) used by the communicators can affect the interlocutors' response and the effects of the communication [see 47-49]. Research has suggested that the informal communication style can soften the hierarchical power relationships, reduce social distance between communicators, and thus can enhance the relationships $[24,50]$. While very little research has examined the impact of informality of brand communication on consumer engagement in social media contexts, recent research has suggested that communicating in a conversational style can enhance consumers' interactivity with a brand and in turn increase their evaluation of the brand $[15,51]$. Thus, we derive the following hypothesis:

H3: Informality of brand posts is positively related to consumer engagement.

\section{Methodology}

\subsection{Data collection}

We selected Facebook as our research context because more than 80 million businesses have created their brand pages on the platform [52], which makes Facebook the most popular social media marketing communication channel worldwide. Similar to previous research [see 14], the top 50 brands of the Interbrand's 100 Best Global Brands in 2017 were used as our research sample. Three brands were excluded because they did not have a Facebook page, did not post any contents during our data collection periods, or did not post in English. For brands with multiple Facebook pages, only the official page with the most fans was selected for data collection.

We used the Facebook Graph API to collect the brand posts. Netvizz, a free application that extracts data from Facebook, was used to collect data [53]. We limited our data collection from 2017 and beyond to reduce the possible noise resulting from the platform changes made by Facebook. For each brand, we collected the brand posts updated between June 1, 2017 and November 30, 2017. For brand pages that consumers are allowed to post on, only posts posted by brands were collected. Data collection was conducted on January 15, 2018, which is one and half months (at least) from the actual posting time, to filter out the possible change in consumer engagement after being recorded $[9,14,54]$. In total, we collected 6,243 posts. Then we removed the automatically updated posts (e.g., brand $x x$ updated their cover photo/profile picture, brand $x x$ added a new photo/cover video, and brand $x x$ shared yy's post/video/photo), posts that are not in English, and posts without text messages which resulted in 6,011 posts. We further excluded 5 brands because they posted less than 5 posts during our date collection periods. Our final dataset included 5,997 Facebook posts from 42 brands that represent 14 industries (as classified by Interbrand), such as automotive, technology, and luxury (see Table 1).

Table 1. Description of dataset 


\begin{tabular}{lccc}
\hline Industry & Number of brands & Number of posts & Avg. number of followers \\
\hline Alcohol & 1 & 9 & $14,623,165$ \\
Apparel & 1 & 19 & $29,501,035$ \\
Automotive & 9 & 1434 & $14,595,887$ \\
Beverages & 2 & 10 & $72,306,190$ \\
Business Services & 1 & 88 & 514,510 \\
Consumer Packaged Goods & 2 & 308 & $17,998,754$ \\
Diversified & 3 & 308 & $3,945,460$ \\
Financial Services & 6 & 604 & $2,002,340$ \\
Leisure & 1 & 334 & $50,086,032$ \\
Luxury & 1 & 82 & $20,450,768$ \\
Restaurants & 1 & 161 & $75,571,219$ \\
Retail & 3 & 594 & $28,504,840$ \\
Technology & 10 & 1847 & $19,259,076$ \\
Transportation & 1 & 199 & $1,766,608$ \\
\hline
\end{tabular}

\subsection{Operationalization of variables}

Positive emotionality and negative emotionality were measured using the percentages of positive and negative emotional words in the brand posts. Linguistic Inquiry and Word Count (LIWC) was used to code positive and negative emotional words in brand posts. We followed previous research [see 12, 36, 43, 55] and measured complexity in terms of five post features: 1) post length (total number of words per post); 2) average sentence length (average number of words per sentence); 3 ) long words (percentage of words that are six or more characters); 4) percentage of hashtags; and 5) percentage of at-mentions. Similar to previous research [24], we measured informality using four linguistic features that are common in brand social media posts including: 1) percentage of emojis (e.g., $\because, \mathcal{\bullet}$, and 5 , 2) percentage of contractions (e.g., "that's", "you're", and "we're"), 3) percentage of informal punctuations (e.g., “..." and "!"), and 4) percentage of personal pronouns (e.g., we, us, you).

We measured consumer engagement using popular social media metrics including: the number of likes, shares, and comments associated with each brand post. Since different brand pages have different numbers of followers and posts updated by brands with more followers might generate more consumer engagement than those with fewer followers, we controlled for the impact of follower size by using the relative number of likes, shares, and comments (i.e., number of like, shares, and comments divided by the number of followers, multiplied by 10,000 ).

We first controlled for the industry since consumer engagement varies across industries [58-59] (see Table 1). Second, we controlled for the posting time, namely, weekday $(n=4,992)$ vs. weekend $(n=1,005)$ because research has shown that Facebook users are more active during the weekday than weekend [9]. Therefore, consumers might be more engaged with brand posts on weekday than weekend. Third, we controlled for the post type, i.e., status $(\mathrm{n}=29)$, link $(\mathrm{n}=1029)$, photo $(\mathrm{n}$ = 2446), video $(n=2477)$, and event $(n=16)$ since different post types generate different levels of media richness and interactivity, which, in turn, can influence the consumer engagement with brand posts $[25,34,56-$ 59]. The descriptive statistics for the variables are shown in Table 2.

Table 2. Descriptive statistics

\begin{tabular}{llrrrr}
\hline Variable & Notation & Mean & SD & Minimum & Maximum \\
\hline Dependent Variables & & & & & \\
$\quad$ Consumer Engagement & & & & & \\
$\quad$ Like & LIKE & 8.98 & 129.00 & 0 & 5356.14 \\
$\quad$ Share & SHARE & .61 & 5.25 & 0 & 212.92 \\
$\quad$ Comment & COMMENT & .14 & .98 & 0 & 42.81 \\
\hline $\begin{array}{l}\text { Independent Variables } \\
\text { Emotionality }\end{array}$ & & & & \\
$\quad \begin{array}{l}\text { Positive Emotion Words } \\
\quad \text { Negative Emotion Words }\end{array}$ & EMOT $_{1}$ & .04 & .05 & 0 & .50 \\
$\quad$ CMOT $_{2}$ & .01 & .02 & 0 & .67 \\
$\quad \begin{array}{l}\text { Postexity length } \\
\text { Average sentence length }\end{array}$ & COMP $_{1}$ & 29.44 & 23.97 & 1 & 381 \\
$\quad$ COMP $_{2}$ & 12.50 & 6.49 & 1 & 52
\end{tabular}




\begin{tabular}{|c|c|c|c|c|c|}
\hline Long words & $\mathrm{COMP}_{3}$ & .22 & .10 & 0 & 1 \\
\hline Hashtag & $\mathrm{COMP}_{4}$ & .03 & .06 & 0 & 1 \\
\hline At-mention & $\mathrm{COMP}_{5}$ & .00 & .01 & 0 & .20 \\
\hline \multicolumn{6}{|l|}{ Informality } \\
\hline Emojis & $I N F O_{1}$ & .01 & .07 & 0 & 4 \\
\hline Contractions & $\mathrm{INFO}_{2}$ & .02 & .03 & 0 & .50 \\
\hline Informal punctuations & $\mathrm{INFO}_{3}$ & .01 & .03 & 0 & .50 \\
\hline Personal pronouns & $\mathrm{INFO}_{4}$ & .04 & .05 & 0 & .50 \\
\hline \multicolumn{6}{|l|}{ Control Variables } \\
\hline Posting time & TIME & & & & \\
\hline Post media type & $T Y P E_{1-4}$ & & & & \\
\hline Industry & INDUSTRY $Y_{1-13}$ & & & & \\
\hline
\end{tabular}

\subsection{Data Analysis}

3.3.1 Model Specification. Because the three dependent variables (i.e., LIKE, SHARE, COMMENT) are highly skewed, we used their natural logarithmic transformations, i.e., $\operatorname{Ln}($ like +1$), \operatorname{Ln}($ share +1$)$, and $\mathrm{Ln}$ (comment+1), in the following data analyses, which is consistent with previous research $[24,56-57,60]$. We add 1 to avoid taking logs of 0 . Because brand posts were nested within brands, we conducted examinations to determine whether to include a hierarchical structure in the regression analyses. Specifically, we conducted the regressions with and without the hierarchical structure and compared the results. The results revealed that including hierarchical structure in the regressions can significantly improve the fit of our model of likes ($2 L L_{\text {without hierarchical structure }}=13808.49,-2 L L_{\text {with hierarchical }}$ structure $=12605.87, \chi_{\text {change }}^{2}=1202.62, \mathrm{df}_{\text {change }}=1, \mathrm{p}$ $<.001)$, model of shares $\left(-2 L L_{\text {without hierarchical structure }=}=\right.$ $5809.25,-2 L L_{\text {with hierarchical structure }}=5357.48, \chi_{\text {change }}^{2}=$ $\left.451.77, \mathrm{df}_{\text {change }}=1, \mathrm{p}<.001\right)$, and the model of comments $\left(-2 L L_{\text {without hierarchical structure }}=-1505.84,-2 L L_{\text {with }}\right.$ hierarchical structure $=-1614.28, \chi_{\text {change }}^{2}=108.44, \mathrm{df}_{\text {change }}=1$, $\mathrm{p}<.001$ ). Moreover, the intra-class correlation (ICC) measures indicate that $27 \%, 13 \%$, and $5 \%$ of the total variances in the number of likes, shares, and comments, respectively, was accounted for by differences between brands $\left(\mathrm{ICC}_{\text {like }}=.27 ; \mathrm{ICC}_{\text {share }}=.13 ; \mathrm{ICC}_{\text {comment }}=.05\right)$ [61]. These results affirmed the need to include the hierarchical structure in the regressions [61]. Thus, following Hayes's [61] recommendations, we conducted the data analyses by running the regressions with the hierarchical structure using group-mean centered predictors. The statistical models for the brand post $i$ by brand $j$ (using number of likes as an example) are:

Level 1 (Post level):

$$
\begin{aligned}
& \text { (1) } \operatorname{Ln}\left(\operatorname{LIKE}_{\mathrm{ij}}+1\right)=\beta_{0 \mathrm{j}}+\sum_{\mathrm{f}=1}^{2} \beta_{\mathrm{fj}} \mathrm{EMOT}_{\mathrm{fij}-G} \mathrm{GMC}+ \\
& \sum_{\mathrm{g}=1}^{5} \beta_{(\mathrm{g}+2) \mathrm{j}} \mathrm{COMP}_{\mathrm{gij}} \mathrm{GMC}+ \\
& \sum_{\mathrm{h}=1}^{4} \beta_{(\mathrm{h}+7) \mathrm{j}} \mathrm{INFO}_{\mathrm{hij} \_} \mathrm{GMC}+\beta_{12 \mathrm{j}} \mathrm{TIME}_{\mathrm{ij}}+
\end{aligned}
$$

$$
\begin{aligned}
& \sum_{\mathrm{m}=1}^{4} \beta_{(\mathrm{m}+12) \mathrm{j}} \text { TYPE }_{\mathrm{mij}}+ \\
& \sum_{\mathrm{n}=1}^{13} \beta_{(\mathrm{n}+12) \mathrm{j}} \text { INDUSTRY }_{\mathrm{nij}}+\varepsilon_{\mathrm{ij}}
\end{aligned}
$$

Level 2 (Brand level):

(2) $\beta_{0 \mathrm{j}}=\gamma_{00}+\sum_{\mathrm{f}=1}^{2} \gamma_{0 \mathrm{f}} \overline{\mathrm{EMOT}_{\mathrm{fj}}}+$

$\sum_{\mathrm{g}=1}^{5} \gamma_{0(\mathrm{~g}+2)} \overline{\mathrm{COMP}_{\mathrm{gj}}}+\sum_{\mathrm{h}=1}^{4} \gamma_{0(\mathrm{~h}+7)} \overline{\mathrm{INFO}_{\mathrm{hj}}}+\mu_{0 \mathrm{j}}$

(3) $\beta_{\mathrm{fj}}=\gamma_{\mathrm{f} 0}$, with $f$ ranging from 1 to 2

(4) $\beta_{(\mathrm{g}+2) \mathrm{j}}=\gamma_{(\mathrm{g}+2) 0}$, with $g$ ranging from 1 to 5

(5) $\beta_{(\mathrm{h}+7) \mathrm{j}}=\gamma_{(\mathrm{h}+7) 0}$, with $h$ ranging from 1 to 4

(6) $\beta_{12 \mathrm{j}}=\gamma_{120}$

(7) $\beta_{(\mathrm{m}+12) \mathrm{j}}=\gamma_{(\mathrm{m}+12) 0}$, with $m$ ranging from 1 to 4

(8) $\beta_{(\mathrm{n}+16) \mathrm{j}}=\gamma_{(\mathrm{n}+16) 0}$, with $n$ ranging from 1 to 13

Then, the final model can be written as follows:

$$
\begin{aligned}
& \text { (9) } \mathrm{Ln}\left(\mathrm{LIKE}_{\mathrm{ij}}+1\right)=\gamma_{00}+\sum_{\mathrm{f}=1}^{2} \gamma_{0 \mathrm{f}} \overline{\mathrm{EMOT}_{\mathrm{fj}}}+ \\
& \sum_{\mathrm{g}=1}^{5} \gamma_{0(\mathrm{~g}+2)} \overline{\mathrm{COMP}_{\mathrm{gj}}}+\sum_{\mathrm{h}=1}^{4} \gamma_{0(\mathrm{~h}+7)} \overline{\mathrm{INFO}_{\mathrm{hj}}}+ \\
& \sum_{\mathrm{f}=1}^{2} \gamma_{\mathrm{fo}} \mathrm{EMOT}_{\mathrm{fij}} \mathrm{GMC}+ \\
& \sum_{\mathrm{g}=1}^{5} \gamma_{(\mathrm{g}+2) 0} \mathrm{COMP}_{\mathrm{gij}} \mathrm{GMC}+ \\
& \sum_{\mathrm{h}=1}^{4} \gamma_{(\mathrm{h}+7) 0} \mathrm{INFO}_{\mathrm{hij}} \mathrm{GMC}+\gamma_{120} \mathrm{TIME}_{\mathrm{ij}}+ \\
& \sum_{\mathrm{m}=1}^{4} \gamma_{(\mathrm{m}+12) 0} \mathrm{TYPE}_{\mathrm{mij}}+ \\
& \sum_{\mathrm{n}=1}^{17} \gamma_{(\mathrm{n}+16) 0} \mathrm{INDUSTRY}_{\mathrm{nij}}+\varepsilon_{\mathrm{ij}}+\mu_{0 \mathrm{j}}
\end{aligned}
$$

where

Ln(LIKE+1): logarithm transformation of the variable Like

$\mathrm{EMOT}_{\mathrm{f}}$ GMC: group-mean centered measure of the $f^{\text {th }}$ emotionality variable

$\mathrm{COMP}_{\mathrm{g}_{-}} \mathrm{GMC}$ : group-mean centered measure of the $g^{\text {th }}$ complexity variable

$\mathrm{INFO}_{\text {hij_}}$ GMC: group-mean centered measure of the $h^{\text {th }}$ informality variable

TIME: posting time variable

TYPE $_{\mathrm{m}}$ : dummy variable of the post type

INDUSTRY $_{\mathrm{n}}$ : dummy variable of industry

f: number of emotionality variables

g: number of complexity variables

$\mathrm{h}$ : number of informality variables 
$\gamma_{00}$ : brand-level intercepts

$\gamma$ : parameters to be estimated

$\varepsilon_{\mathrm{ij}}$ : random error at the tweet level

$\mu_{0 \mathrm{j}}$ : random error at the brand level

3.3.2 Model Results. The estimation results are presented in Table 3 . We can see from Table 3 that many brand posts' linguistic characteristics significantly impact consumer engagement, but the effects vary regarding the three types of consumer engagement (i.e., like, share, comment). Since our focus of analysis is on the post-level effects of brand linguistic styles, in the following section, we will primarily discuss the findings at the post level.

Emotionality. In terms of emotionality, the results revealed that the emotionality of brand posts is significantly related to the number of likes. Specifically, positive emotionality significantly increases the number of likes $\left(\gamma_{\text {Like, }_{\text {EMOT }}{ }_{1} \text { GMC }}=.40, p<.05\right)$ and negative emotional words significantly decreases the number of likes $\left(\gamma_{\text {Like, } \mathrm{EMOT}_{2} \mathrm{GMC}}=-1.02, p<.05\right)$; thus, supporting $\mathrm{H} 1 \mathrm{a}$ and $\mathrm{H} 1 \mathrm{~b}$. Our results indicated that consumers are influenced by the emotionality of brand posts and that the emotional contagion effect exists in the nonconcurrent brand-to-consumer communications. While previous research has found that both positive and negative emotional messages can trigger more engagement [30, 32], our results revealed that positive and negative emotional words have opposing effects on consumer engagement, indicating a need for further examination of the effects of positive and negative emotions on consumer engagement. The results did not reveal any significant relationships between the emotionality and the number of shares or comments. One possible explanation is that, compared to liking, sharing and commenting are more cognitive-loaded activities that require the high level of involvement; thus, they need stronger stimuli than emotionality of brand posts to be triggered.

Complexity. In terms of complexity, the results revealed that the average sentence length significantly and negatively impacts the number of likes $\left(\gamma_{\text {Like, } \mathrm{COMP}_{2} \mathrm{GMC}}=-.01, p<.001\right)$, shares $\left(\gamma_{\text {Share, } \mathrm{COMP}_{2} \mathrm{GMC}}=-.00, p<.01\right)$ and comments $\left(\gamma_{\text {Comment, } \mathrm{COMP}_{2} \mathrm{GMC}}=-.00, p<.01\right)$. The results also showed that the hashtags significantly and negatively impact the number of likes $\left(\gamma_{\text {Comment, } \mathrm{COMP}_{4}{ }_{\mathrm{GMC}}}=-.92\right.$, $p<.001)$ and shares $\left(\gamma_{\text {Share, } \mathrm{COMP}_{4} \mathrm{GMC}}=-.24, p<.05\right)$. The effects of other complexity variables on other consumer engagement measures are not. Our analysis revealed that the complexity (i.e., at least one complexity variable) of brand posts negatively impacts consumer engagement measures (i.e., like, share, or comment). Thus, H2 was partially supported.

Informality. Inconsistent with our hypothesis, no significant relationship was found between informality variables and consumer engagement Thus, H3 was not supported. One possible explanation is that our data was collected from real social media settings where consumers might already be familiar with and get used to the informal linguistic style. Thus, adopting informal style in brand posts does not significantly influence consumers' engagement behavior.

Control variables. In our analyses, we controlled for the effects of posting time, post type, and industry. Consistent with Sabate et al. [54] and Schultz [57], our results showed that posting time (i.e., weekday vs. weekend) does not impact consumer engagement. Our results did show that, compared to posts with pure textual contents, posts with photos receive significantly higher number of likes $\left(\gamma_{\text {Like, TYPE }_{2}}=.35, p<.01\right)$ and posts with videos receive significantly higher number of likes $\left(\gamma_{\mathrm{Like}_{\mathrm{TYPE}}}=.28, p<.05\right)$ and shares $\left(\gamma_{\mathrm{Share}_{3} \mathrm{TYPE}_{3}}\right.$ $=.18, p<.05)$. Our study also showed that the number of comments vary across industry.

Table 3. Effects of brand post linguistic styles on consumer engagement

\begin{tabular}{lcccccc}
\hline & \multicolumn{2}{c}{ Like } & \multicolumn{2}{c}{ Share } & \multicolumn{2}{c}{ Comment } \\
\cline { 2 - 6 } Variables & $\gamma$ & SE & $\gamma$ & SE & $\gamma$ & SE \\
\hline Intercept & -1.46 & 1.28 & -.48 & .47 & -.07 & .17 \\
$\quad$ Emotionality & & & & & & \\
$\quad$ Positive Emotion Words & $.40^{*}$ & .19 & .14 & .11 & .10 & .06 \\
$\quad$ Negative Emotion Words & $-1.02 *$ & .46 & -.12 & .25 & -.11 & .14 \\
$\quad$ Complexity & & & & & \\
$\quad$ Post length & -.00 & .00 & -.00 & .00 & -.00 & .00 \\
$\quad$ Average sentence length & $-.01 * * *$ & .00 & $-.00 * *$ & .00 & $-.00 * *$ & .00 \\
$\quad$ Long words & -.13 & .10 & -.08 & .05 & -.06 & .03 \\
$\quad$ Hashtag & $-.92 * * *$ & .20 & $-.24 *$ & .11 & -.10 & .06 \\
$\quad$ At-mention & 1.13 & 1.27 & .48 & .69 & .15 & .39 \\
Informality & & & & & & \\
\hline
\end{tabular}




\begin{tabular}{|c|c|c|c|c|c|c|}
\hline Emojis & .18 & .13 & .08 & .07 & .04 & .04 \\
\hline Contractions & -.10 & .27 & .23 & .15 & -.03 & .08 \\
\hline Informal punctuations & .15 & .29 & -.10 & .16 & .05 & .09 \\
\hline Personal pronouns & -.16 & .20 & -.03 & .11 & .01 & .06 \\
\hline \multicolumn{7}{|l|}{ Control variables } \\
\hline Posting time & -.05 & .02 & -.01 & .01 & -.01 & .01 \\
\hline \multicolumn{7}{|l|}{ Post type } \\
\hline Link & .22 & .13 & .06 & .07 & .01 & .04 \\
\hline Photo & $.35^{* *}$ & .13 & .09 & .07 & .02 & .04 \\
\hline Video & $.28^{*}$ & .13 & $.18^{*}$ & .07 & .05 & .04 \\
\hline Event & -.02 & .22 & .01 & .12 & .00 & .07 \\
\hline \multicolumn{7}{|l|}{ Industry } \\
\hline Alcohol & .99 & .90 & -.14 & .34 & -.02 & .13 \\
\hline Apparel & 1.13 & .73 & .39 & .27 & .03 & .10 \\
\hline Automotive & -.10 & .47 & -.11 & .17 & -.10 & .06 \\
\hline Beverages & -.22 & .74 & .04 & .29 & -.01 & .11 \\
\hline Business Services & .42 & .62 & .03 & .22 & $-.21 *$ & .08 \\
\hline Consumer Packaged Goods & .01 & .65 & -.24 & .23 & -.15 & .08 \\
\hline Diversified & -.39 & .51 & -.29 & .18 & $-.18 * *$ & .06 \\
\hline Financial Services & -.00 & .50 & -.29 & .18 & $-.16^{*}$ & .06 \\
\hline Leisure & -.51 & 1.03 & -.38 & .37 & -.09 & .13 \\
\hline Luxury & -.12 & .72 & -.40 & .26 & -.13 & .09 \\
\hline Restaurants & -.64 & .70 & -.22 & .25 & $-.19 *$ & .09 \\
\hline Retail & -.24 & .62 & -.24 & .23 & -.13 & .08 \\
\hline Technology & -.66 & .50 & -.35 & .18 & $-.18 * *$ & .06 \\
\hline
\end{tabular}

$*: \mathrm{p}<0.05 ; * *: \mathrm{p}<0.01 ; * * *: \mathrm{p}<0.001$

\section{Discussion and Conclusion}

This paper investigates the impacts of brand posts' linguistic styles (i.e., emotionality, complexity, and informality) on consumer engagement. Our findings revealed that brand posts' linguistic style significantly impact consumer engagement, but the effects vary regarding likes, shares, and comments (see Table 4).
One possible explanation is that, like, share, and comment are three engagement behaviors with different levels of involvement [7]. While brand posts' linguistic characteristics can impact all of the three engagement behaviors, their effects are not large enough to greatly change highly-involving engagement behaviors (i.e., share, comment). The findings suggest that like, share and comment are three different consumer engagement behaviors that need to be studied individually.

Table 4. Summary of hypotheses testing results

\begin{tabular}{|c|c|c|c|c|}
\hline \multirow{2}{*}{ Hypothesis } & \multirow{2}{*}{ Expected } & \multicolumn{3}{|c|}{ Results } \\
\hline & & Like & Share & Comment \\
\hline Emotionality & & Supported & Not Supported & Not Supported \\
\hline Positive Emotionality & $(+)$ & $(+)$ & & \\
\hline Negative Emotionality & $(-)$ & $(-)$ & & \\
\hline Complexity & & Partially & Partially & Partially \\
\hline & & Supported & Supported & Supported \\
\hline Post length & $(-)$ & & & \\
\hline Average sentence length & $(-)$ & $(-)$ & $(-)$ & $(-)$ \\
\hline Long words & $(-)$ & & & \\
\hline Hashtag & $(-)$ & $(-)$ & $(-)$ & \\
\hline At-mention & $(-)$ & & & \\
\hline Informality & & Not Supported & Not Supported & Not Supported \\
\hline Emojis & $(+)$ & & & \\
\hline Contractions & $(+)$ & & & \\
\hline Informal punctuations & $(+)$ & & & \\
\hline Personal pronouns & $(+)$ & & & \\
\hline
\end{tabular}




\subsection{Theoretical and managerial implications}

This paper addresses recent calls for research on effective brand social media content strategies [3-4] and brand linguistics [16]. Different from previous research on consumer engagement with brand posts on social media, where the post characteristics such as content type, media type, and posting timing, were mainly examined, this paper investigates the effects of linguistic styles on consumer engagement with brand posts on social media. It extends the theoretical generalizability of CAT by applying the theory to a brand-to-consumer communication occurring in the social media context.

Social media has become a critically important communication channel for marketers. While consumer engagement is the most prevalent target for social media marketing, marketing practitioners are struggling with effective content strategies. Our findings show that social media marketers need to carefully consider the linguistic styles of their brand posts and, to enhance consumer engagement, some linguistic styles need to be incorporated while others avoided. For example, social media marketers could use more positively emotional words and less complex expressions to enhance consumer engagement.

\subsection{Limitations and future research}

This paper is not without limitations. First, due to the limitation of access to Facebook data, we did not mitigate the potential impacts of the Facebook algorithm and paid audience-targeting posts on posts exposure and engagement in our model. With Facebook data access, future research could test and validate our findings by taking real posts view number into account. Second, in this paper, we measured post emotionality using LIWC. While LIWC is one of the widely used method to determine emotionality of text messages, it has its own limitations. For instance, LIWC does not distinguish between positive or negative contexts. Future research could incorporate other sentiment analysis approaches or even manual content analysis approaches to validate the measurement of post emotionality. Third, in this paper, we focused on the impacts of linguistic styles on consumer engagement with brand posts without investigating why consumers respond differently to different linguistics styles or how different consumers react differently to the same linguistic style. Future research could explore the underlying process as well as how the underlying process varies with different consumers. Fourth, in this paper we did not consider the interaction effects of linguistic characteristics. Future research could examine the engagement levels for combinations of variables, for example, how a post that is both emotional and complex impact engagement levels. Lastly, our research was conducted in the context of Facebook brand pages, where, although often including images and videos, the main delivery mechanism for brand posts is textual message. In this case, it is not surprising that linguistic styles can influence consumer engagement behavior. However, in other social media platforms where textual messages are not at the heart of brand posts, such as Instagram (where brand posts are usually centered in photos) and YouTube (where brand posts are usually centered in videos), it would be worth exploring whether effects of linguistic styles still exist.

\section{Reference}

[1] R. Dolan, J. Conduit, J. Fahy, and S. Goodman, "Social media engagement behaviour: a uses and gratifications perspective", Journal of Strategic Marketing, 24(3-4), 2016, pp. 261-277.

[2] S. Chung, A. Animesh, K. Han, and A. Pinsonneault, "Firms' Social Media Efforts, Consumer Behavior, and Firm Performance: Evidence from Facebook", Proceedings of the 35th International Conference on Information Systems, 2014.

[3] V. Kumar, "Evolution of marketing as a discipline: What has happened and what to look out for", Journal of Marketing, 79(1), 2015, pp. 1-9.

[4] Marketing Science Institute, Research Priorities 20182020. Marketing Science Institute, Cambridge, Massachusetts, 2018.

[5] C.K. Coursaris, W. van Osch, and B.A. Balogh, "Do Facebook likes lead to shares or sales? Exploring the empirical links between social media content, brand equity, purchase intention, and engagement", Proceedings of the 49th Hawaii International Conference on System Sciences, 2016, pp. 3546-3555.

[6] R.E. Cruz, J.M. Leonhardt, and T. Pezzuti, "Second Person Pronouns Enhance Consumer Involvement and Brand Attitude", Journal of Interactive Marketing, 39, 2017, pp. 104-116.

[7] L. de Vries, S. Gensler, and P.S. Leeflang, "Effects of traditional advertising and social messages on brandbuilding metrics and customer acquisition", Journal of Marketing, 81(5), 2017, pp. 1-15.

[8] K. Hutter, J. Hautz, S. Dennhardt, and J. Füller, "The impact of user interactions in social media on brand awareness and purchase intention: the case of MINI on Facebook", Journal of Product \& Brand Management, 22(5/6), 2013, pp. 342-351.

[9] T.F. Wagner, C.V. Baccarella, and K.I. Voigt, "Framing social media communication: Investigating the effects of brand post appeals on user interaction", European Management Journal, 35(5), 2017, pp. 606-616.

[10] A. Kumar, R. Bezawada, R. Rishika, R. Janakiraman, and P.K. Kannan, "From social to sale: The effects of firm- 
generated content in social media on customer behavior", Journal of Marketing, 80(1), 2016, pp. 7-25.

[11] C. Ashley, and T. Tuten, "Creative strategies in social media marketing: An exploratory study of branded social content and consumer engagement", Psychology \& Marketing, 32(1), 2015, pp. 15-27.

[12] D. Lee, K. Hosanagar, and H.S. Nair, "Advertising content and consumer engagement on social media: evidence from Facebook", Management Science, 64(11), 2018, pp. 5105-5131.

[13] eMarketer. "Retailers get bragging rights for Facebook interaction", $\quad$ Retrieved from http://www.emarketer.com/Article/Retailers-BraggingRights-Facebook-Interaction/1012313, 2015.

[14] D.H. Kim, L. Spiller, and M. Hettche, "Analyzing media types and content orientations in Facebook for global brands", Journal of Research in Interactive Marketing, 9(1), 2015, pp. 4-30.

[15] A. Jakic, M.O. Wagner, and A. Meyer, "The impact of language style accommodation during social media interactions on brand trust", Journal of Service Management, 28(3), 2017, pp. 418-441.

[16] M. Carnevale, D. Luna, and D. Lerman, "Brand linguistics: A theory-driven framework for the study of language in branding", International Journal of Research in Marketing, 34(2), 2017, pp. 572-591.

[17] H. Giles, N. Coupland, and J. Coupland, "Accommodation theory: Communication, context and consequence", In H. Giles, J. Coupland and N. Coupland (Eds.), Contexts of accommodation (pp. 1-68). Cambridge University Press, Cambridge, England, 1991.

[18] K. Muir, A. Joinson, R. Cotterill, and N. Dewdney, "Linguistic Style Accommodation Shapes Impression Formation and Rapport in Computer-Mediated Communication", Journal of Language and Social Psychology, 36(5), 2017, pp. 525-548.

[19] L.E. Scissors, A.J. Gill, and D. Gergle, "Linguistic mimicry and trust in text-based CMC", Proceedings of the 2008 ACM Conference on Computer Supported Cooperative Work, 2008, pp. 277-280.

[20] R.I. Swaab, W.W. Maddux, and M. Sinaceur, "Early words that work: When and how virtual linguistic mimicry facilitates negotiation outcomes", Journal of Experimental Social Psychology, 47(3), 2011, pp. 616621.

[21] S. Ludwig, K. De Ruyter, M. Friedman, E.C. Brüggen, M. Wetzels, and G. Pfann, "More than words: The influence of affective content and linguistic style matches in online reviews on conversion rates", Journal of Marketing, 77(1), 2013, pp. 87-103.

[22] S. Steinmann, G. Mau, and H. Schramm-Klein, "Brand communication success in online consumption communities: An experimental analysis of the effects of communication style and brand pictorial representation", Psychology \& Marketing, 32(3), 2015, pp. 356-371.

[23] P. Aggarwal, and A.L. McGill, "When brands seem human, do humans act like brands? Automatic behavioral priming effects of brand anthropomorphism", Journal of Consumer Research, 39(2), 2012, pp. 307-323.

[24] A. Gretry, C. Horváth, N. Belei, and A.C. van Riel, "'Don't pretend to be my friend!' When an informal brand communication style backfires on social media", Journal of Business Research, 74, 2017, pp. 77-89.

[25] L. Kwok, and B. Yu, "Spreading social media messages on Facebook: An analysis of restaurant business-toconsumer communications", Cornell Hospitality Quarterly, 54(1), 2013, pp. 84-94.

[26] J.D. Morris, "Theories of emotion and affect in marketing communications", In S. Rodgers \& E. Thorson (Eds.), Advertising Theory (pp. 85-104). Routledge, New York, 2012.

[27] D. Derks, A.H. Fischer, and A.E. Bos, "The role of emotion in computer-mediated communication: A review", Computers in Human Behavior, 24(3), 2008, pp. 766-785.

[28] M.J. Hine, S.A. Murphy, and V. Ambwani, "Emotional Contagion in Computer Mediated Communication", The International Journal of Knowledge, Culture and Change Management. 10(6), 2010, pp. 149-163.

[29] A.D. Kramer, J.E. Guillory, and J.T. Hancock, "Experimental evidence of massive-scale emotional contagion through social networks", Proceedings of the National Academy of Sciences, 111(24), 2014, pp. 87888790 .

[30] J. Kissler, C. Herbert, P. Peyk, and M. Junghofer, "Buzzwords: early cortical responses to emotional words during reading", Psychological Science, 18(6), 2007, pp. 475-480.

[31] J. Berger, and K.L. Milkman, "What makes online content viral?", Journal of Marketing Research, 49(2), 2012, pp. 192-205.

[32] S. Stieglitz, and L. Dang-Xuan, "Emotions and information diffusion in social media-sentiment of microblogs and sharing behavior", Journal of Management Information Systems, 29(4), 2013, pp. 217248.

[33] E. Joyce, and R.E. Kraut, "Predicting continued participation in newsgroups", Journal of ComputerMediated Communication, 11(3), 2006, pp. 723-747.

[34] A.J. Kim, and K.K. Johnson, "Power of consumers using social media: Examining the influences of brand-related user-generated content on Facebook", Computers in Human Behavior, 58, 2016, pp. 98-108.

[35] K. Swani, and G.R. Milne, "Evaluating Facebook brand content popularity for service versus goods offerings", Journal of Business Research, 79, 2017, pp. 123-133.

[36] J. Arguello, B.S. Butler, E. Joyce, R. Kraut, K.S. Ling, C. Rosé, and X. Wang, "Talk to me: foundations for successful individual-group interactions in online communities", Proceedings of the SIGCHI Conference on Human Factors in Computing Systems, 2006, pp. 959968.

[37] C. Burgers, E.A. Konijn, G.J. Steen, and M.A. Iepsma, "Making ads less complex, yet more creative and persuasive: The effects of conventional metaphors and irony in print advertising", International Journal of Advertising, 34(3), 2015, pp. 515-532.

[38] P. Chatterjee, "The role of varying information quantity in ads on immediate and enduring cross-media synergies", Journal of Marketing Communications, 18(3), 2012, pp. 217-240. 
[39] A. Ghose, and P.G. Ipeirotis, "Estimating the helpfulness and economic impact of product reviews: Mining text and reviewer characteristics", IEEE Transactions on Knowledge and Data Engineering, 23(10), 2011, pp. 1498-1512.

[40] Z. Liu, and S. Park, "What makes a useful online review? Implication for travel product websites", Tourism Management, 47, 2015, pp. 140-151.

[41] P. Anand, and B. Sternthal, "Ease of message processing as a moderator of repetition effects in advertising", Journal of Marketing Research, 27(3), 1990, pp. 345-353.

[42] M.B. Jensen, and A.L. Jepsen, Low attention advertising processing in B2B markets. Journal of Business \& Industrial Marketing, 22(5), 2007, pp. 342-348.

[43] Q. Jones, G. Ravid, and S. Rafaeli, "Information overload and the message dynamics of online interaction spaces: A theoretical model and empirical exploration", Information Systems Research, 15(2), 2004, pp. 194-210.

[44] T. McArthur, Concise Oxford companion to the English language. Oxford University Press, Oxford, UK, 2003.

[45] R.W. Ruekert, and O.C. Walker Jr, "Marketing's interaction with other functional units: A conceptual framework and empirical evidence", Journal of Marketing, 51(1), 1987, pp. 1-19.

[46] A. Mosquera, and P. Moreda, "A qualitative analysis of informality levels in web 2.0 texts: The facebook case study", Proceedings of the LREC workshop: @ NLP can u tag\# user generated content, 2012, pp. 23-28.

[47] A.S.I. Lenoir, S. Puntoni, and S.M. van Osselaer, "What Shall I Call Thee? the Impact of Brand Personality on Consumer Response to Formal and Informal Address", Advances in Consumer Research, 42, 2014, pp. 136-140.

[48] J. Otterbacher, C.S. Ang, M. Litvak, and D. Atkins, "Show Me You Care: Trait Empathy, Linguistic Style, and Mimicry on Facebook", ACM Transactions on Internet Technology, 17(1), 2017, Article 6.

[49] G.G. Scott, J. Sinclair, E. Short, and G. Bruce, "It's not what you say, it's how you say it: language use on Facebook impacts employability but not attractiveness", Cyberpsychology, Behavior, and Social Networking, 17(8), 2014, pp. 562-566.

[50] J. Delin, "Brand Tone of Voice: a linguistic analysis of brand positions", Journal of Applied Linguistics, 2(1), 2005, pp. 1-44.
[51] C.J. Beukeboom, P. Kerkhof, and M. de Vries, "Does a virtual like cause actual liking? How following a Brand's Facebook updates enhances brand evaluations and purchase intention", Journal of Interactive Marketing, 32 , 2015, pp. 26-36.

[52] P. Cooper, "41 Facebook Stats That Matter to Marketers in 2019", Retrieved from: https://blog.hootsuite.com/facebook-statistics/\#business, 2018.

[53] B. Rieder, "Studying Facebook via data extraction: the Netvizz application", Proceedings of the 5th Annual ACM Web Science Conference, 2013, pp. 346-355.

[54] F. Sabate, J. Berbegal-Mirabent, A. Cañabate, and P.R. Lebherz, "Factors influencing popularity of branded content in Facebook fan pages", European Management Journal, 32(6), 2014, pp. 1001-1011.

[55] G. Venturi, T. Bellandi, F. Dell'Orletta, and S. Montemagni, "NLP-Based Readability Assessment of Health-Related Texts: A Case Study on Italian Informed Consent Forms", Proceedings of the Sixth International Workshop on Health Text Mining and Information Analysis, 2015, pp. 131-141.

[56] L. de Vries, S. Gensler, and P.S. Leeflang, "Popularity of brand posts on brand fan pages: an investigation of the effects of social media marketing", Journal of Interactive Marketing, 26(2), 2012, pp. 83-91.

[57] C.D. Schultz, "Proposing to your fans: Which brand post characteristics drive consumer engagement activities on social media brand pages?", Electronic Commerce Research and Applications, 26, 2017, pp. 23-34.

[58] S.S.I. Lei, S. Pratt, and D. Wang, "Factors influencing customer engagement with branded content in the social network sites of integrated resorts", Asia Pacific Journal of Tourism Research, 22(3), 2017, pp. 316-328.

[59] P. Luarn, Y.F. Lin, and Y.P. Chiu, "Influence of Facebook brand-page posts on online engagement", Online Information Review, 39(4), 2015, pp. 505-519.

[60] I.P. Cvijikj, and F. Michahelles, "Online engagement factors on Facebook brand pages", Social Network Analysis and Mining, 3(4), 2013, pp. 843-861.

[61] A.F. Hayes, "A primer on multilevel modeling", Human Communication Research, 32(4), 2006, pp. 385-410 